\title{
PENGARUH PERSEPSI LINGKUNGAN SEKOLAH TERHADAP PRESTASI BELAJAR PPKn SISWA SMA NEGERI PANDEGLANG BANTEN
}

\author{
E. Nita Prianti \\ Universitas Banten Jaya \\ Serang, Indonesia \\ nitaprianti18@gmail.com
}

\begin{abstract}
The Effect of School Environment Perception on the Achievement of Learning of PPKN Student of SMA Negeri 6 Pandeglang Banten. This research is conducted to take a purpose one of them is to know how far the influence of school environment perception (X1) to student's learning achievement $(Y)$ so that the result obtained by one in learning and perceives according to capacity (ability, competence, and ability) it has. The method used in this research is the correlation method that is part of the type of quantitative research. Population in this research is student / student of class XI SMA Negeri 6 Pandeglang which amounted to 720 students. The sample in this research is 180 students taken by random sampling. The result of this research is the influence of school environment perceptions on the achievement of PPKN student of SMA Negeri 6 Pandeglang significantly. This is proved by the acquisition of tcount $=4.049$ and Sig. 0,000 $<0.05$. Variable perception of school environment gives contribution of 30,10\% to improvement of learn ing achievement of PPKN. Thus that there is influence of school environment perception to student achievement.
\end{abstract}

Keywords: school environment, school environment perception, learning achievement

\section{PENDAHULUAN}

Pada dasarnya, seluruh manusia memerlukan pendidikan. Tanpak pendidikan, manusia akan menemukan kesulitandalam menghadapi masalah kehidupan.Pendidikan diibaratkan lampu penerang kehidupan bagi anak didik bahkan seluruh manusia, pendidikan tidak hanya berfungsi mentransmisi kebudayaan kepada generasi penerus, akan tetapi pendidikan juga berfungsi sebagai menstransformasikan kebudayaan agar sesuai dengan perkembangan dan tujuan serta tuntutan zaman. Dengan kata lain pendidikan sangat berperan dalam membuka wawasan dan pengetahuan anak didik dalam berbagai ilmu pengetahuan dengan melalui belajar.
Belajar merupakan interaksi antara keadaan internal dan proses kognitif siswa dengan stimulus dari lingkungan, yang kemudian proses kognitif tersebut menghasilkan suatu hasil belajar. Hasil belajar tersebut terdiri dari informasi verbal, keterampilan intelek, keterampilan motorik, sikap dan siasat kognitif (Dimyati, 2015). Sedangkan menurut Ngalim Purwanto (2003) bahwa belajar merupakan perubahan dalam tingkah laku melalui latihan atau pengalaman yang disebabkan oleh pertumbuhan atau kematangan serta pengalaman yang berulang. Dalam kegiatan interaksi belajar mengajar guru membelajarkan siswa dengan harapan bahwa pembelajaran tersebut siswa dapat menghasilkan suatu 
perubahan yang bertahap dalam dirinya, baik dalam bidang pengetahuan, keterampilan dan sikap.

Adanya perubahan tersebut terlihat dalam prestasi belajar yang dihasilkan oleh siswa berdasarkan evaluasi yang diberikan oleh guru.Sekolah merupakan lembaga pendidikan formal yang tidak hanya memberikan pengetahuan tetapi juga menanamkan nilai-nilai dan budi pekerti. Siswa adalah sebagai objeknya yang terlibat dalam kegiatan belajar-mengajar di sekolah yang dapat dilihat dari beberapa segi, yaitu usia, kondisi keluarga, minat dan bakat anak didik serta tingkat inteligensinya. Dengan mengetahui semuanya itu, maka tindakan pendidik akan mengutamakan fleksibilitas dalam mendidik. Dalam proses kegiatan tersebut siswa mengalami tindak mengajar dan kemudian meresponnya.

Di dalam proses belajar mengajar tersebut, siswa menggunakan kemampuan mentalnya untuk mempelajari bahan belajar, kemampuan tersebut meliputi kemampuan kognitif, afektif, dan psiomotorik (Dimyati, 2015:22).

Dalam latar pendidikan, proses belajar-mengajar di sekolah seyogianya mengemban sekurang-kurangnya dua misi, yakni membelajarkan peserta didik dengan efisien dan efektif, dan serentak dengan itu, meningkatkan kemauan dan kemampuan belajar mandiri, merancang dan mengimplementasikan program belajar mengajar sehingga terdorong sebagai basis dari belajar sepanjang hayat. Dengan kata lain, dapat terbentuk manusia dan masyarakat yang mau dan mampu terus menerus belajar (Tirtarahardja, 2005).

Dalam proses kegiatan pendidikan tentunya ada pihak yang harus bertanggung jawab di dalamnya. Penanggung jawab pendidikan di sekolah yang terlibat di dalamnya salah satuanya adalah para guru. Guru sangat berperan penting dalam dunia pendidikan yang merupakan pilar utama terhadap pengembangan manusia dan masyarakat suatu bangsa. Menurut Kartono (1995 : 6) mengemukakan bahwa "guru dituntut untuk menguasai bahan pelajaran yang akan diajarkan, dan memiliki tingkah laku yang tepat dalam mengajar." Oleh sebab itu guru harus dituntut untuk menguasai bahan pelajaran yang disajikan dan memiliki metode yang tepat pula dalam mengajar.

Di samping itu, lingkungan yang efektif siswa akan menjadi produktif seperti berpikir berkreasi dan mampu belajar secara aktif yang dikarenakan lingkungan yang sangat mendukung seperti contoh lainnya, seorang pelajar merasa senang ketika akan datang ke 
sekolahnya, dikarenakan pada pikirannya tergambar sebuah ruangan kelas yang nyaman, pengajar-pengajar yang baik, dan berkompeten, teman-teman yang baik, fasilitas-fasilitas yang lengkap dan mendukung, sehingga dia mampu berpikir produktif. Bekerja sama dengan temanbelajarnya, mampu menyerap informasi yang disampaikan. Inilah sebuah gambaran dimana sebuah lingkungan belajar mampu mengefektifkan keadaannya dan mendorong terciptanya sebuah proses belajar mengajar yang produktif.

Pendidikan diharapkan dapat mengusahakan pembentukan manusia Pancasila sebagai manusia pembangunan yang tinggi kualitasnya serta memberikan dukungan bagi masyarakat, bangsa, dan Negara (Undang-undang:1992). Landasan pendidikan tersebut akan memberikan pijakan dan arah terhadap pembentukan manusia, serentak dengan itu, mendukung perkembangan masyarakat bangsa dan Negara (Tirtaraharja, 2005)

Dengan menerapkan wawasan pendidikan yang tepat, asas pendidikan yang tepat pula, maka akan dapat memberikan peluang yang lebih besar dalam merancang dan menyelenggarakan program pendidikan yang tepat pula. Maka wawasan itu akan memberikan perspektif yang lebih luas terhadap pendidikan baik dalam aspek konseptual maupun oprasional.

Dalam persoalan pendidikan yang harus dikembangkan untuk mengangkat harkat martabat bangsa, serta membebaskan bangsa dari ketergantungan terhadap bangsa lain adalah pendidikan yang dapat mengembangkan potensi masyarakat secara optimal, membangun masyarakat secara utuh dan menyeluruh.Pendidikan yang mampu menghasilkan sumber daya manusia berkualitas dan pandangan yang jauh kedepan dengan mementingkan bangsa dan negara dalam berbagai aspek kehidupan.

Mata pelajaran PPKN merupakan mata pelajaran yang mempelajari tentang manusia selain sebagai makhluk individu yang mempunyai karakter khas masingmasing sehingga berbeda dengan manusia yang lain, selain sebagai makhluk individu manusia juga sebagai makhluk sosial yang selalu berkelompok dan berinteraksi dengan manusia yang lainnya, dalam wadah keluarga, bangsa dan Negara.Melalui mata pelajaran PPKn peserta didik diarahkan untuk dapat menjadi warga Negara Indonesia yang demokratis, bertanggung jawab, berpartisipasi, serta warga dunia yang cinta damai.Pengajaran PPKn di sekolah dapat membangkitkan kesadaran siswa dalam hidup bermasyarakat, berbangsa dan 
bernegara, sehingga tumbuh adanya kesadaran kolektif dalam memiliki kebersamaan dalam kehidupan sosial. Jadi, pemahaman kesadaran ilmu Pendidikan Kewarganegaraan merupakan titik awal dari timbulnya rasa memahami kehidupan bermasyarakat dan nilai-nilai sosial kemanusiaan, harga diri, kebersamaan, dan keterikatan (sense of solidarity), rasa keterpautan dan rasa memiliki (sense of belonging), kemudian rasa bangga (sense of pride) terhadap bangsa dan tanah air sendiri. Dengan penelitian ini diharapkan akan diperoleh manfaat: Untuk mengetahuipengaruh persepsi lingkungan sekolah terhadap prestasi belajar PPKN siswa kelas XI SMA Negeri 6 Pandeglang.

\section{METODE PENELITIAN}

Penelitian ini dilaksanakan pada siswa/siswi kelas XI SMA Negeri 6 Pandeglang, tahun ajaran 2014.

Berdasarkan variabel yang diteliti, maka peneliti menggunakan metode survey dengan analisis korelasi ganda yang merupakan bagian dari jenis penelitian kuantitatif. Penelitian yang digunakan adalah penelitian analisis deskriptif yaitu suatu metode penelitian yang mengambil sampel dari suatu populasi dan menggunakan kuesioner sebagai alat pengumpul data.
Menurut Suharsimi Arikunto (2006:108) populasi adalah keseluruhan obyek penelitian. Menurut Suharsimi Arikunto (2006:134) “apabila subyeknya kurang dari 100, diambil semua sekaligus sehingga penelitiannya adalah penelitian populasi. Jika jumlah subyeknya besar, maka diambil 10\%-15\% atau 20\%-25\% atau lebih."

Berdasarkan penjelasan diatas maka populasi dalam penelitian ini adalah siswa/siswi kelas XI SMA Negeri 6 Pandeglang, yang berjumlah 720 siswa. Dengan demikian maka peneliti akan menentukan jumlah sampel dalam penelitian berdasarkan pendapat Arikunto yaitu diambil $25 \%$ untuk dijadikan sebagai sampel. Oleh karena itu, berdasarkan perhitungan yang telah dilakukan oleh peneliti maka sampel penelitian ini adalah 180 siswa yang diambil secara random sampling.

Metode pengumpulan data dalam penelitian ini mempergunakan metode angket dan kuesioner. Agar mempernudah melakukan penelitian di lapangan. Sehingga dapat memberikan gambaran yang kongkrit dalam penelitian ini.

Adapun teknik pengambilan data yang digunakan dalam penelitian ini adalah sebagai berikut :

a. Mendapatkan data tentang prestasi belajar PPKN dengan mengambil dari 
dokumen guru berupa nilai raport (dokumentasi)

b. Teknik mendapatkan data persepsi pada lingkungan sekolah dilakukan dengan cara menyebar angket kepada siswa yang menjadi sampel.

Secara oprasional persepsi siswa pada lingkungan sekolah merupakan skor hasil pengukuran tentang aspirasi yang dimiliki seorang siswa pada lingkungan sekolah. Indicator dari pengukuran persepsi siswa

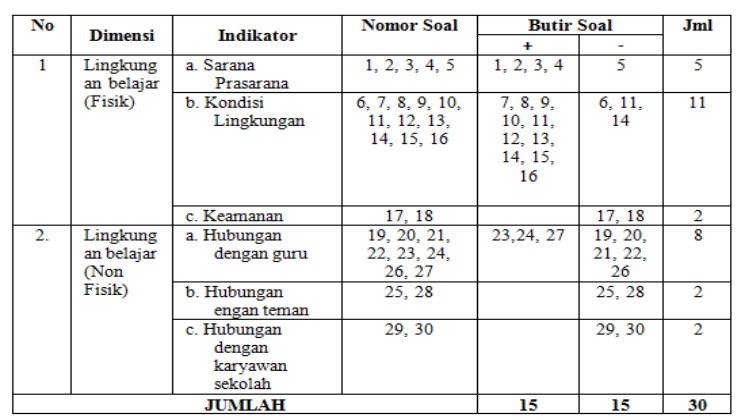

dipengaruhi oleh guru, siswa, fasilitas dan kurikulum.

Kisi-kisi Instrumen Persepsi Siswa

Tabel 1. Kisi-Kisi Instrumen Variabel

Persepsi atas Lingkungan Sekolah

Kalibrasi instrumen variabel motivasi belajar

\section{Uji Validitas}

Uji validitas adalah suatu pengujian instrumen yang digunakan untuk mengukur tingkat keandalan atau kesahihan suatu alat ukur yang digunakan dalam penelitian. Untuk menguji Validiatas instrumen maka terlebih dahulu dicari nilai korelasi antara bagian-bagian tersebut secara keseluruhan dengan cara mengkorelasikan setiap butir alat ukur dengan skor total yang merupakan jumlah tiap skor tiap butir dengan rumus Person Product Moment.

Rumus : $\mathrm{r}_{\mathrm{xy}}=\frac{N \sum X Y-\left(\sum X\right)\left(\sum Y\right)}{\sqrt{\left(N \sum X^{2}-\left(\sum X^{2}\right)\right\}\left\{N \sum Y^{2}-\left(\sum Y^{2}\right)\right]}}$

Keterangan :

$\mathrm{r}_{\mathrm{xy}}$ : Koefisien korelasi product moment

$\Sigma X$ : Jumlah skor dalam sebaran $\mathrm{X}$

$\Sigma Y$ : Jumlah skor dalam sebaran $\mathrm{Y}$

$\Sigma X^{2}$ : Jumlah skor yang dikuadratkan dalam sebaran $\mathrm{X}$

$\Sigma \mathrm{Y}^{2}$ : Jumlah skor yang dikuadratkan dalam sebaran $\mathrm{Y}$

$\mathrm{N}$ : Banyaknya responden

$r_{\text {hitwing }}=\frac{r \sqrt{\mathrm{n}-2}}{\sqrt{1-T^{2}}}$

Selanjutnya dihitung dengan menggunakan uji-t dengan rumus:

Distribusi table-t untuk $\alpha=0,05$ dan derajat kebebasan $(\mathrm{dk}=\mathrm{n}-2)$ kaidah keputusan sebagai berikut :

- jika $\mathrm{t}$ hitung $>\mathrm{t}$ table berarti instrumen tersebut valid

- jika $\mathrm{t}$ hitung $<\mathrm{t}$ table berarti instrument tersebut tidak valid

Uji reliabilitas

Uji ini dilakukan untuk mengukur apakah suatu instrumen dapat dipercaya untuk digunakan sebagai alat pengumpul data. untuk mengukur reliabilitas maka digunakan rumus Alpha Cronbach Rumusnya adalah:

$$
r_{11}=\left(\frac{n}{n-1}\right)\left(1-\frac{\sum \sigma_{i}^{2}}{\sigma_{t}^{2}}\right)
$$


Berdasarkan hasil perhitungan diperoleh hasil bahwa dari 30 butir instrument motivasi belajar yang diujicobakan,7 butir pernyataan drof, yaitu nomor $1,3,5,17,19,21$, dan 22. Sehingga instrument yang dipakai untuk sampel sebanyak 23 butir dengan tingkat reliabilitas 0,933 .

Teknik analisis statistik adalah pengujian data hasil penelitian yang dilakukan dengan menyajikan data dalam bentuk perhitungan statistik dasar yang meliputi tabel distribusi frekwensi, histogram, nilai rata-rata, median, modus, simpangan baku dengan rumusan sebagai berikut :

a. Rata - Rata $=\frac{\sum X}{n}$

Keterangan : $\quad \mathrm{x}=$ rata-rata $\mathrm{x}=$ jumlah tiap data $\mathrm{n}=$ jumlah data

b. Median $=M e=1 / 2(n+1)$ dimana $n$ $=$ jumlah data

c. Modus $\quad=b+p\left(\frac{b_{1}}{b_{1}+b_{2}}\right)$

Keterangan :

Mo = Nilai modus

$\mathrm{b} \quad=$ Batas bawah nilai yang mengandung nilai modus

$\mathrm{P} \quad=$ Panjang kelas nilai modus

$\mathrm{b}_{1}=$ Selisih antara frekwensi modus dengan frekwensi sebelumnya $\mathrm{b}_{2}=$ Selisih antara frekwensi modus dengan frekwensi sesudahnya.

d. Simpangan baku $\sqrt{\frac{{ }^{n} \sum x^{2}-\left(\sum x\right)^{2}}{n(n-1)}}$ atau $\mathrm{s}=\sqrt{\frac{\sum x^{2}}{n-1}}$

Proses perhitungan dilakukan dengan bantuan program SPSS Ver.13.0 dan Microsoft Excel 2007.

\section{HASIL PENELITIAN DAN PEMBAHASAN}

Data Persepsi Siswa atas Lingkungan Sekolah (X1)

Data persepsi siswa atas lingkungan sekolah diperoleh dari kuisioner yang di jawab oleh 180 orang responden dihasilkan skor terendah 23, skor tertinggi 90, skor rerata sebesar 57,81, median sebesar 60, modus sebesar 64 dan simpangan baku sebesar 17,031.

Tabel 2. Deskripsi data Penelitian Persepsi siswa atas lingkungan sekolah

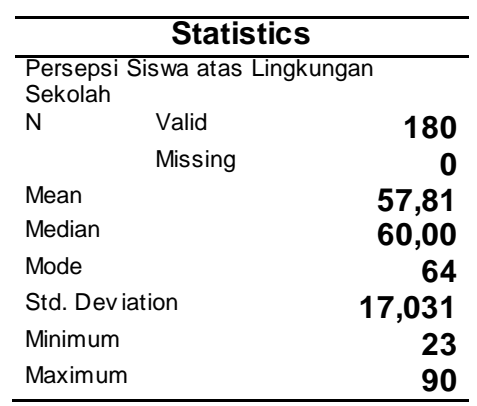

Dari hasil perhitungan diatas , maka bisa dikatakan bahwa Persepsi siswa atas lingkungan sekolahsiswa SMA Negeri 6 Pandeglang kurang baik. Hal ini di indikasikan dengan perolehan skor rerata 57,81.Untuk memperjelas data di atas, digambarkan dalam histogram sebagai berikut : 
$\mathrm{H}_{1}$ : Terdapat pengaruh persepsi siswa atas lingkungan sekolah terhadap prestasi Belajar PPKN

Dari table 5. dapat dinyatakan bahwa terdapat pengaruh persepsi siswa atas lingkungan sekolah terhadap prestasi Belajar PPKNsecara sangat signifikan. Hal ini dapat dibuktikan dengan perolehan nilai $t_{\text {hitung }}=4,049$ dan Sig. $0,000<0,05$. Dari table statistik juga dapat menjelaskan bahwa variable persepsi siswa atas lingkungan sekolah memberikan kontribusi sebesar $30,10 \%$ terhadap peningkatan prestasi Belajar PPKN.

\section{KESIMPULAN}

Berdasarkan hasil analisa data yang diuraikan di atas, maka dapat diambil kesimpulan sebagai berikut:

Terdapat pengaruh persepsi siswa atas lingkungan sekolah terhadap prestasi Belajar IPS secara sangat signifikan. Hal dini dibuktikan dengan perolehan nilai $t_{\text {hitung }}=4,049$ dan Sig. $0,000<0,05$. Variable persepsi siswa atas lingkungan sekolah memberikan kontribusi sebesar $30,10 \%$ terhadap peningkatan prestasi Belajar PPKN.

\section{DAFTAR PUSTAKA}

\section{a. Buku}

Arikunto,Suharsimi. 2006. Prosedur Penelitian suatu Pendekatan Praktek. Jakarta: Rineka Cipta.
Dimyati dan Mudjiono. (2015). Belajar dan Pembelajaran. Jakarta: Rineka Cipta

Kartono, Kartini. 1995. Psikologi Anak (Psikologi Perkembangan). Bandung : CV. Mandar Maju.

Purwanto, M. Ngalim. 2000. Psikologi Pendidikan. Bandung: PT. Remaja Rosdakarya.

Tim Penyusun Kamus Pusat Pembinaan dan Pengembangan Bahasa. 1999. Kamus Besar Bahasa Indonesia. Jakarta: Balai Pustaka.

Tirtarahardja Umar. 2005. Pengantar Pendidikan. Jakarta: Rineka Cipta

\section{b. Perundang-undangan}

Undang-Undang RI No. 20 Tahun 2003 Tentang Sistem Pendidikan Nasional 